\title{
Effects of droplet size and spray volume parameters on droplet deposition of wheat herbicide application by using UAV
}

\author{
Changfeng Shan ${ }^{1}$, Guobin Wang ${ }^{1 *}$, Haihong Wang ${ }^{2}$, Yingjie Xie ${ }^{1}$, Huizheng Wang ${ }^{1}$, \\ Shilong Wang ${ }^{3}$, Shengde Chen ${ }^{4}$, Yubin Lan $^{1,4,5^{*}}$ \\ (1. College of Agricultural Engineering and Food Science, Shandong University of Technology, Shandong Provincial \\ Engineering Technology Research Center for Agricultural Aviation Intelligent Equipment, Zibo 255022, Shandong, China; \\ 2. Corteva Agroscience Technology (Shanghai) Co., Ltd, Shanghai 201203, China; \\ 3. Zibo Agricultural and Rural Service Center, Zibo 255022, Shandong, China; \\ 4. National Center for International Collaboration Research on Precision Agricultural Aviation Pesticides Spraying Technology \\ (NPAAC), Ministry of Science and Technology, College of Electronics Engineering, South China Agricultural University, \\ Guangzhou 510642, China; \\ 5. Department of Biological and Agricultural Engineering, Texas A\&M University, College Station, TX 77845, USA)
}

\begin{abstract}
With the characteristic of flexible and precise, unmanned aerial vehicles (UAVs) for low volume applications are increasing substantially and quickly around the globe. However, little attention has been paid to the study of wheat herbicides with UAV, especially the research on the spray volume and droplet size of the herbicide sprayed by UAVs. The objectives of this study were to compare the droplet deposition from a typical commercial UAV under four different spray volumes of 7.5 L/hm $\mathrm{hm}^{2}, 15.0 \mathrm{~L} / \mathrm{hm}^{2}, 22.5 \mathrm{~L} / \mathrm{hm}^{2}$, and $30.0 \mathrm{~L} / \mathrm{hm}^{2}$ and three different volume median diameter (VMD) of $150 \mu \mathrm{m}, 200 \mu \mathrm{m}$, and $300 \mu \mathrm{m}$ during winter wheat weeding period. DepositScan software was used to analyze droplet deposition parameters including the percentage of spray coverage and the number of droplets in various sampling positions. The test results showed that the droplet deposition was effected by each factor and their interactions. When the spray volume was $7.5 \mathrm{~L} / \mathrm{hm}^{2}$, the effect of VMD on the percentage of spray coverage was not significant. However, these variation rules were changed to smaller droplets with greater coverage when the spray volume higher than $15.0 \mathrm{~L} / \mathrm{hm}^{2}$. In all treatments, the number of droplets increased with decreasing VMD or increasing spray volume. The maximum percentage of spray coverage and the number of droplets that were achieved under the VMD of $150 \mu \mathrm{m}$ and the spray volume of $30.0 \mathrm{~L} / \mathrm{hm}^{2}$ were $12.8 \%$ and 40.0 droplets $/ \mathrm{cm}^{2}$, respectively. The variation coefficients of the percentage of spray coverage and the number of droplets were $29.0 \%-73.3 \%$ and $20.2 \%-54.1 \%$, respectively. The most uniform deposition was achieved under the spray volume of $15.0 \mathrm{~L} / \mathrm{hm}^{2}$ and the VMD of $150 \mu \mathrm{m}$. The results revealed the effect of droplet size and spray volume parameters on droplet deposition, which was useful for guiding farmers on how to use UAVs for weeding in winter wheat fields.
\end{abstract}

Keywords: unmanned aerial vehicle, spray volume, droplet size, droplet deposition

DOI: $10.25165 /$ j.ijabe.20211401.6129

Citation: Shan C F, Wang G B, Wang H H, Xie Y J, Wang H Z, Wang S L, et al. Effects of droplet size and spray volume parameters on droplet deposition of wheat herbicide application by using UAV. Int J Agric \& Biol Eng, 2021; 14(1): 74-81.

\section{Introduction}

The application of agrochemical is an indispensable part of crop production in modern agriculture and contributes to increasing

\section{Received date: 2020-08-29 Accepted date: 2020-11-08}

Biographies: Changfeng Shan, Master candidate, research interest: agricultural engineering, Email: 18503150239@stumail.sdut.edu.cn; Haihong Wang, Master, research interest: agricultural pharmacology, Email: Pamela.wang@corteva.com; Yingjie Xie, Master candidate, research interest: agricultural engineering, Email: 784353836@qq.com; Huizheng Wang, PhD, research interest: agricultural aviation application, Email: hzwang@sdut.edu.cn; Shilong Wang, Master, research interest: agricultural pharmacology, Email: zbsws1@163.com; Shengde Chen, $\mathrm{PhD}$, research interest: agricultural aviation application, Email: shengde-chen@scau.edu.cn.

*Corresponding author: Guobin Wang, $\mathrm{PhD}$, research interest: agricultural aviation application. College of Agricultural Engineering and Food Science, Shandong University of Technology, Zibo 255022, Shandong, China. Tel: +86-13265503065, Email: guobinwang@sdut.edu.cn; Yubin Lan, PhD, research interest: agricultural aviation application. College of Agricultural Engineering and Food Science, Shandong University of Technology, Zibo 255022, Shandong, China. Tel: +86-533-2782718, Email: ylan@sdut.edu.cn. productivity and yield quality ${ }^{[1,2]}$. At present, semi-mechanical operation and traditional manual spraying are still the main methods of plant protection in China. It led to a low utilization rate and excessive spraying of pesticides and caused serious pesticide residues and environmental pollution ${ }^{[3-5]}$. According to reports, the use of pesticides in China was about 2.5 times the world average, and the arable area contaminated with pesticides accounted for about $1 / 10$ of the arable area ${ }^{[6]}$.

The crop protection unmanned aerial vehicle (UAV) was a new pesticide spraying technology adapted to the development of modern agriculture. Compared with traditional ground spray technology, UAVs have the advantages of high flexibility, efficiency, and no-harm to the ground crops ${ }^{[7,8]}$. Compared with traditional manned aircraft, UAVs do not require a special airport, which is suitable for working in small plots. These advantages make sense to use UAVs for spray applications that they can operate over sodden fields and tall crops where very few machines could normally move, fly quickly to exact locations to treat target areas precisely, and also be pre-programmed to navigate their own way around. Furthermore, the use of a low or ultra-low spray 
volume can reduce pesticide use by $20.0 \%-30.0 \%$, which can be used as an important technical support for the pesticide reduction program of China ${ }^{[9,10]}$.

With various advantages and providing massive benefits for farmers, UAV application technology has become a research hotspot. The effects of spray parameters ${ }^{[11-14]}$, crop types ${ }^{[11,15,16]}$, spray system ${ }^{[17-19]}$, and meteorological conditions ${ }^{[15,20]}$ on the droplet deposition of UAV application were widely studied. Zhu et al. ${ }^{[14]}$ used a spray experiment platform to study the effects of three variables (rotor speed, spray height, and nozzle speed) on the deposition characteristics and droplet size. The results showed that the spray height had a significant effect on the deposition, while the effect on the droplet size was negligible. However, the influence of the wind field on the droplet deposition was not considered. Chen et al. ${ }^{[15]}$ used a single-rotor UAV to study the effect of wind fields in the $X, Y$, and $Z$ directions ( $X$ direction: parallel to the flight direction; $Y$ direction: perpendicular to the flight direction; $Z$ direction: perpendicular to the ground direction) on droplet deposition in the rice canopy. The results showed that the wind field in the $Y$ and $Z$ directions had a good linear relationship with the droplet deposition. Wang et al. ${ }^{[21]}$ studied the effect of different wind speeds on droplet deposition and found that the higher the wind speed, the fewer the droplets deposited. Hunter et al. ${ }^{[20]}$ found that droplet deposition was also affected by atmospheric stability. They studied the effect of different atmospheric stability on droplet deposition, and the results showed that stable atmospheric conditions can increase droplet deposition $^{[22]}$. Moreover, the crop structure also affects the droplet deposition. Zhang et al. ${ }^{[16]}$ studied the effect of different canopy structures of citrus trees on droplet deposition. The results indicated that the droplet distribution of the hedgerow-shaped and the open-center-shaped canopy by the UAV spraying achieved a better performance than that of the round-head-shaped plants. Wang et al. ${ }^{[11]}$ used UAV to study the droplet deposition on wheat crops and found that the droplet deposition in the upper canopy was larger than that of the middle and lower layers. The spray system was the most important factor affecting droplets deposition. Jee et al. ${ }^{[17]}$ designed a UAV spraying system, which can automatically adjust the spray speed and spray width to improve the uniformity of droplet deposition.

Insecticides and fungicides generally have certain systemic properties, but post-emergence herbicides require more contact with weeds and higher application techniques. Among all application parameters, the spray volume and the droplet size were the most important because they play an important role in the control efficacy, which should be defined before spraying ${ }^{[23]}$. This conclusion was especially important in herbicidal applications ${ }^{[24]}$. Butts et al. ${ }^{[25]}$ used ground machinery to study the effects of droplet size $(150-900 \mu \mathrm{m})$ and spray volume $\left(\geq 47.0 \mathrm{~L} / \mathrm{hm}^{2}\right)$ on the control efficacy of dicamba and glyphosate. The results showed that the control effect of herbicide decreased with the increase of droplet size and spray volume. Droplet size and carrier volume are interrelated and major factors of herbicide coverage and performance, although the influence of the specific species being targeted, crop canopy, and herbicides must also be considered ${ }^{[24]}$. Berger et al. ${ }^{[26]}$ studied the effect of XR and AI nozzles on droplet percentage of spray coverage by large spray volume and found that the percentage of spray coverage was $47.0 \%$ and $28.0 \%$, respectively. In terms of weeding performance, the control efficacy of XR nozzles in the treatment area was higher than that of AI nozzles in the treatment area. In addition, the crop canopy structure affects the control efficacy of herbicides on weeds ${ }^{[24]}$. This is particularly an issue with winter annual grasses, whose small, narrow leaves and ability to grow within the wheat canopy makes their control more difficult ${ }^{[27]}$. The suitable spray volume and droplet size also effected by the type of herbicides. Creech et al. ${ }^{[28]}$ studied the effects of different types of herbicides on post-emergence herbicidal and found that control effects varied with different herbicides. When using contact herbicides, the applicator should use a larger spray volume to maximize herbicide efficacy. Each herbicide and weed species interaction requires a tailored approach to maximize efficacy ${ }^{[29]}$.

Although the effects of spray volume and droplet size on deposition and herbicide efficacy were extensively studied, previous studies were mainly focused on large volume applications. Because the tank capacity and flight speed of a UAV sprayer are limite $\mathrm{d}^{[5]}$, only low volume spray is used during spraying. A lot of studies are performed on the effects of UAV application parameters on droplet distribution and control efficacy for crop pests and diseases. Little attention has paid to the study of wheat herbicide with UAV, letting alone for spray volume and droplet size of UAV spraying herbicide. It is worthy of further study on whether the wheat herbicide application of UAV with low volume can achieve a good droplet deposition effect and the optimal spray volume and droplet size of a UAV spraying. Hence, field tests were conducted to test the effect of spray volume and droplet size on droplet deposition during the winter wheat herbicide application period. The Kromekote ${ }^{\mathbb{R}}$ cards $(20 \mathrm{~mm} \times 80 \mathrm{~mm})$ were used to collect the droplet deposition and allure red was used as a tracer. After application, DepsoitScan software was used to analyze droplet deposition parameters including the percentage of spray coverage (\%) and the number of droplets (deposits $\left./ \mathrm{cm}^{2}\right)$ in various sampling positions.

\section{Materials and methods}

\subsection{Experimental site}

The experiment was carried out at Huantai City, Shandong Province $\left(118^{\circ} 1^{\prime} 20^{\prime \prime} \mathrm{E} ; 37^{\circ} 0^{\prime} 15^{\prime \prime} \mathrm{N}\right)$, China, during November 2019. The location is shown in Figure 1. The tested crop was "Jimai 44" wheat in the 3rd leaf growth stages and the sowing time was October 2019. The plant spacing, plant height, and planting density were $20.0 \mathrm{~cm},(7.0 \pm 1.0) \mathrm{cm}$, and $3.5 \times 10^{6}$ plants $/ \mathrm{hm}^{2}$, respectively. At the time of the experiment, it was in the pre-winter wheat weeding period. The weed type in the field was mainly broad-leaved weed, and the weed density was 1520 plants $/ \mathrm{m}^{2}$.

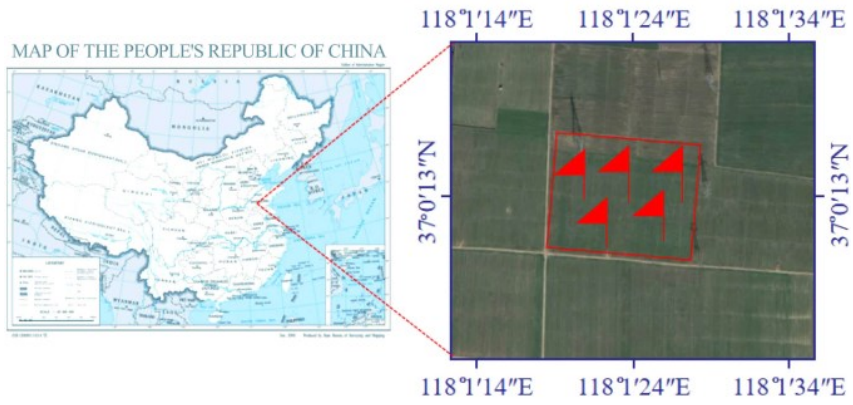

Figure 1 Experiment location and a brief overview of the studied wheat field (marked with red flags)

The meteorological conditions were recorded using a weather meter (Model NK-5500, Nielsen-Kellerman Co., Boothwyn, PA, 209 USA), which indicated temperatures of $13.7^{\circ} \mathrm{C}-15.8^{\circ} \mathrm{C}$, relative humidity of $47.0 \%-62.2 \%$, and wind velocities of $0-0.4 \mathrm{~m} / \mathrm{s}$ during 
the deposition test.

\subsection{Sprayers}

The P30 UAV sprayer is a four-rotor electrical-powered aircraft (XAG Co., Ltd., China), which provides a flight time of about 15 minutes for one charge. The spraying equipment is shown in Figure 2. P30 UAV uses high precision real-time kinematic differential positioning technology, with the accuracy of the flying height and velocity controlled within centimeter-level, respectively. It can automatically fly according to a pre-programmed route. The spray width, flight speed and flight height of the UAV can also be set through the handheld ground controller. The UAV spray system was equipped with a $10.0 \mathrm{~L}$ capacity tank, centrifugal atomization nozzles, a peristaltic pump, and a flowmeter. The centrifugal atomization nozzles were mounted under each rotor. The nozzle rotational speed varies from $0-16000 \mathrm{r} / \mathrm{min}$ at different voltages, and the droplet size produced by the nozzle decreases with increasing rotational speed. Some detailed parameters of the spraying equipment are shown in Table 1.

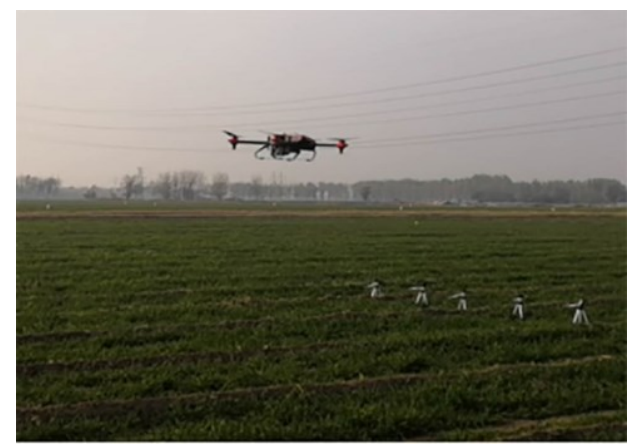

Figure 2 XAG P30 four-rotor electric unmanned aerial vehicle

Table 1 Technical parameters for the UAV sprayer

\begin{tabular}{lc}
\hline \multicolumn{1}{c}{ Classification } & Parameters \\
\hline Dimensions $/ \mathrm{mm}$ & $1180 \times 1180 \times 410$ \\
Nozzle number & 4 \\
Nozzle type & Centrifugal nozzle \\
Nozzle spacing $/ \mathrm{mm}$ & 1050 \\
Tank capacity $/ \mathrm{L}$ & 10.0 \\
Spraying width $/ \mathrm{m}$ & 3.0 \\
Flight speed $/ \mathrm{m} \cdot \mathrm{s}^{-1}$ & 3.0 \\
Spraying height $/ \mathrm{m}$ & 2.0 \\
\hline
\end{tabular}

\subsection{Experimental design}

The herbicide used in this experiment was Quelex ${ }^{\circledR}(10 \%$ halauxifen-methyl and 10\% florasulam water dispersible granule) produced by Corteva ${ }^{\mathrm{TM}}$ agriscience Company, USA. The experimental field was about $44 \mathrm{~m} \times 30 \mathrm{~m}$. The experiment consisted of 12 treatments. In the experiment, the effect of spray volumes and droplet sizes on the spray deposition was studied. The XAG P30 UAV used four different spray volumes of 7.5 L/hm ${ }^{2}, 15.0 \mathrm{~L} / \mathrm{hm}^{2}, 22.5 \mathrm{~L} / \mathrm{hm}^{2}$, and $30.0 \mathrm{~L} / \mathrm{hm}^{2}$, and three different droplet sizes of $150 \mu \mathrm{m}, 200 \mu \mathrm{m}, 300 \mu \mathrm{m}$. These four spray volumes $\left(7.5 \mathrm{~L} / \mathrm{hm}^{2}, 15.0 \mathrm{~L} / \mathrm{hm}^{2}, 22.5 \mathrm{~L} / \mathrm{hm}^{2}\right.$, and $\left.30.0 \mathrm{~L} / \mathrm{hm}^{2}\right)$ and three different volume median diameters (VMD) of $150 \mu \mathrm{m}$, $200 \mu \mathrm{m}$ and $300 \mu \mathrm{m}$ are the most industry-representative spray volumes and volume median diameter, as these are the most commonly used volumes and volume median diameter in spray service companies. Table 2 shows the details of each treatment test.

To analyze the influence of different droplet sizes and spray volumes on the deposition, the sampling points were arranged as shown in Figure 3. As three repetitions, droplet sampling was arranged in three lines spaced equally apart and the same sampling point arrangement was set up in the test area, and the distance between the sampling lines was $10 \mathrm{~m}$. The sampling points were arranged under two routes at the core position of the test area. Each sampling line has 7 droplet sampling points, the distance between the sampling points was $1 \mathrm{~m}$, and the total length was $6 \mathrm{~m}$, which was exactly equal to two swaths width of the tested UAV. The sampling points were marked from left to right, the first sampling point was marked as $0 \mathrm{~m}$, and the last one was marked as $6 \mathrm{~m}$. The Kromekote ${ }^{\circledR}$ cards were fixed horizontally on a plastic platform at each sampling point, which was used to measure the droplet deposition (the number of droplets and percentage of spray coverage). The plastic platforms were fixed on the tripod with the help of a double-headed clamp. By adjusting the height of the tripod, the Kromekote ${ }^{\circledR}$ card was about $10 \mathrm{~cm}$ from the wheat canopy. After spraying, the Kromekote ${ }^{\circledR}$ cards on the plastic platform were replaced for further analysis. The field test is shown in Figure 4.

Table 2 Parameters of each treatment

\begin{tabular}{ccc}
\hline Treatment & Droplet size $/ \mu \mathrm{m}$ & Spray volume $/ \mathrm{L} \cdot \mathrm{hm}^{-2}$ \\
\hline 1 & & 7.5 \\
2 & 150 & 15.0 \\
3 & & 22.5 \\
4 & & 30.0 \\
\hline 5 & 200 & 7.5 \\
6 & & 15.0 \\
7 & & 22.5 \\
8 & & 30.0 \\
\hline 9 & & 7.5 \\
10 & 300 & 15.0 \\
11 & & 22.5 \\
12 & & 30.0 \\
\hline
\end{tabular}

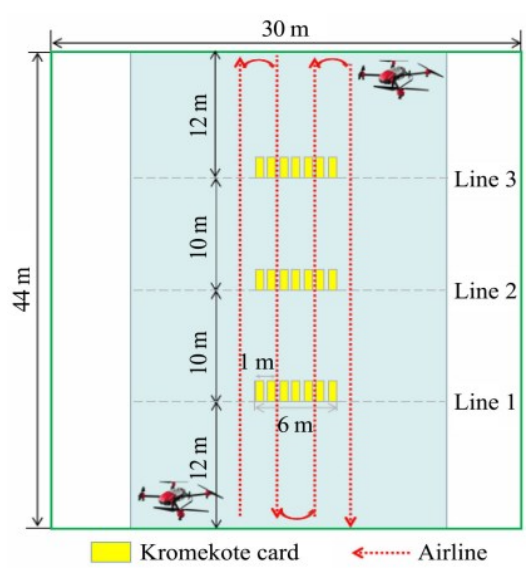

Figure 3 Sampling point arrangement

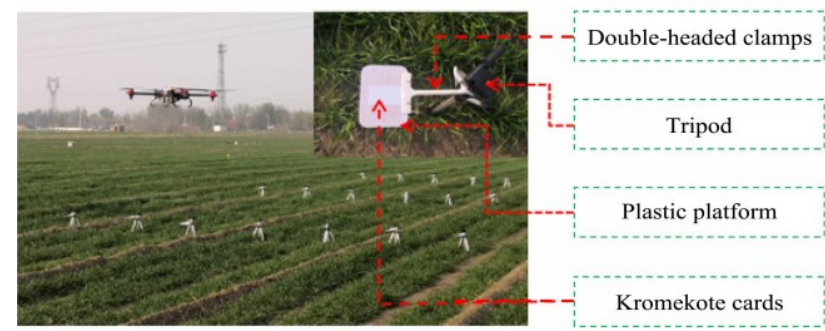

Figure 4 Test setup in the field 


\subsection{Measurement of droplet deposition}

Before application, $15.0 \mathrm{~g} / \mathrm{L}$ of Allura Red (80\% purity, purchased from Beijing Oriental Care Trading Ltd, China) was added to the tank using as the tracer. Allure red, a water-soluble colorant, was frequently used in these types of studies ${ }^{[30,31]}$. Nearly $30 \mathrm{~s}$ after spraying, the replaced Kromekote ${ }^{\circledR}$ cards were collected in a zip-lock bag and taken to the laboratory for processing. Kromekote ${ }^{\circledR}$ cards were scanned at a resolution of 600 dpi with a scanner (Model GT-1500 Seiko Epson Corporation, Japan). Then, use the imagery software DepositScan (USDA, Wooster, OH, USA) to obtain the droplet deposition (the number of droplets and percentage of spray coverage) on the Kromekote ${ }^{\circledR}$ $\operatorname{card}^{[32]}$.

\subsection{Data analysis}

The significant difference was obtained using analysis of variance (two-way ANOVA) by Duncan's test at a significance level of 95\% with SPSS v17.0 (SPSS Inc, an IBM Company, Chicago, IL, USA), and Excel software (Microsoft Office 2019, Microsoft Corporation, Redmond, Washington, USA) calculated the coefficient of variation. The coefficient of variation (CV) was used to show the uniformity of droplet deposition ${ }^{[33]}$ and can be presented as follow. The lower the coefficient of variation is, the better the uniformity of the droplet distribution.

$$
\begin{gathered}
C V=\frac{S}{\bar{X}} \times 100 \% \\
S=\sqrt{\sum_{i=1}^{n}\left(X_{i}-\bar{X}\right)^{2} /(n-1)}
\end{gathered}
$$

where, $S$ is the standard deviation of the samples in the same test group; $X_{i}$ is the number of droplets or percentage of spray coverage of each sampling point; $\bar{X}$ is the mean value of the samples in the same test group; $n$ is the number of sampling points in each test group.

\section{Results and discussion}

\subsection{Percentage of spray coverage}

The percentage of spray coverage is an important parameter of droplet deposition and an important indicator of evaluating spray effectiveness. Figure 5 shows the percentage of spray coverage of droplets varied from different spray volumes and droplet sizes. When the spray volume was $7.5 \mathrm{~L} / \mathrm{hm}^{2}$, the percentage of spray coverage increases with the increase of droplet size, but there was no significant difference $(p=0.061)$. When the spray volumes were $\geq 15.0 \mathrm{~L} / \mathrm{hm}^{2}$, this conclusion was reversed. The percentage of spray coverage decreased with the increase of droplet size and there was a significant difference $(p=0.000)$. Meanwhile, under the same droplet size, the percentage of spray coverage increased with the increase of the spray volume $(p=0.000)$. Therefore, the percentage of spray coverage of droplet was not only affected by the droplet size and spray volume, but also by the interaction of these two factors $(p=0.004)$.

Theoretically, when the spray volume was unchanged, the droplet size of the droplet is reduced by 1 time, the number of droplets is increased by 8 times $^{[25]}$, the specific surface area of the droplet is significantly increased, and the percentage of spray coverage is increased. However, the decrease in droplet size can significantly increase the evaporation of droplets and lead to a decrease in coverage. When the spray volume was $7.5 \mathrm{~L} / \mathrm{hm}^{2}$, it may be that the evaporation of droplets played a major role. After the release of the droplet, a certain amount of evaporation will occur before being deposited on the target. Compared with large droplets, small droplets have weaker resistance to evaporation. When the spray volume was $\geq 15.0 \mathrm{~L} / \mathrm{hm}^{2}$, the small droplets increased the percentage of spray coverage and played a major role, so that the percentage of spray coverage decreased with the increasing of the droplet size. Knoche et al. ${ }^{[24]}$ found that in the spraying experiment studies that the percentage of spray coverage decreased with the increase of droplet size. This was different from our conclusion, which may be due to the different spray volume from our experiment. Chen et al. ${ }^{[6]}$ found that the percentage of spray coverage increased with the increase of the droplet size in the lower volume application. That was mainly caused by the drift of droplets. In our experiment, the environmental wind speed was closed to 0 , and the effect of drift on the deposition of the droplet was weak, that was why it had different conclusions. Meanwhile, the spray volume also has a great effect on the percentage of spray coverage. Wang et al. ${ }^{[11]}$ used UAV to study the effect of three spray volumes $\left(9.0 \mathrm{~L} / \mathrm{hm}^{2}, 16.8 \mathrm{~L} / \mathrm{hm}^{2}\right.$, and $28.1 \mathrm{~L} / \mathrm{hm}^{2}$ ) on the percentage of spray coverage, and found that the percentage of spray coverage increased with the increase of spray volume, which was consistent with the results of this study.

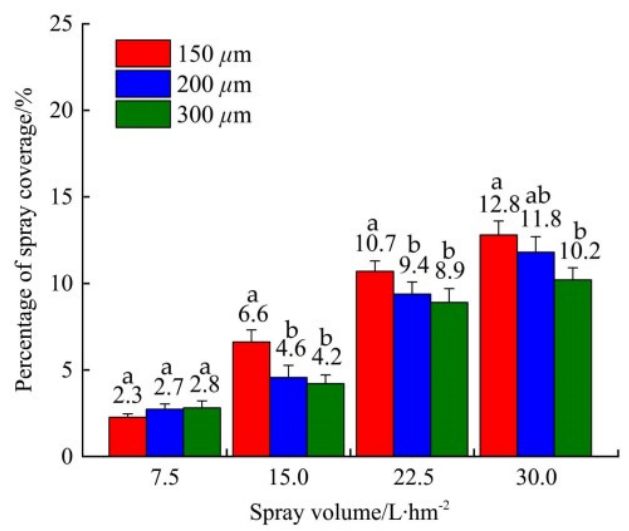

Note: Lowercase letters represent the significant difference in the percentage of spray coverage of different droplet sizes under the same spray volume.

Figure 5 Percentage of spray coverage under different spray volume

The interaction between spray volume and droplet size resulted in different percentages of spray coverage, which had an important effect on herbicide efficacy. A review by Knoche et al. ${ }^{[24]}$ showed that in $71 \%$ of herbicide spray test, the efficacy of the herbicide increased with a decrease in droplet size. In the $44 \%$ herbicide spray test, the herbicide efficacy increased with the increase of spray volume. The herbicidal effect of small droplets was higher at lower volume applications, however, the droplet size had little effect on herbicidal efficacy at large spray volume ${ }^{[25,34]}$. This may be since the small droplets can increase the spray coverage at lower volume applications, while droplet size has less influence on coverage at high spray volume. The percentage of spray coverage has different effects on contact or systemic herbicides. Contact herbicides require the use of small droplets to increase spray coverage and achieve maximum control efficacy ${ }^{[24]}$. However, this conclusion was not consistent ${ }^{[35,36]}$, which may be related to the physicochemical properties of the herbicide and the target object-related. Systemic herbicides can achieve good control effects without too much percentage of spray coverage. Therefore, the effects of spray volume and droplet size on herbicidal efficacy should be based on the specific application environment.

\subsection{The number of droplets}

The number of droplets was one of the standards for evaluating spray quality. Figure 6 shows the number of droplets in different 
treatments. When the spray volume was consistent, the number of droplets decreased with the increase of the droplet size, and there was a significant difference $(p=0.000)$. When the spray volumes were $7.5 \mathrm{~L} / \mathrm{hm}^{2}, 15.0 \mathrm{~L} / \mathrm{hm}^{2}, 22.5 \mathrm{~L} / \mathrm{hm}^{2}, 30.0 \mathrm{~L} / \mathrm{hm}^{2}$, the number of droplets range at different droplet sizes were 4.4-9.9 droplets $/ \mathrm{cm}^{2}$, 4.5-19.6 droplets $/ \mathrm{cm}^{2}, 8.6-35.4$ droplets $/ \mathrm{cm}^{2}, 8.8-40.0$ droplets $/ \mathrm{cm}^{2}$, respectively. The number of droplets increased with the increase of the spray volume $(p=0.000)$. When the droplet sizes were $150 \mu \mathrm{m}, 200 \mu \mathrm{m}, 300 \mu \mathrm{m}$, the number of droplets range at different spray volumes were 9.9-40.0 droplets $/ \mathrm{cm}^{2}, 5.7-16.8$ droplets $/ \mathrm{cm}^{2}$, 4.4-8.8 droplets $/ \mathrm{cm}^{2}$, respectively. Meanwhile, the interaction of the droplet size and the spray volume on the number of droplets was also significant $(p=0.000)$.

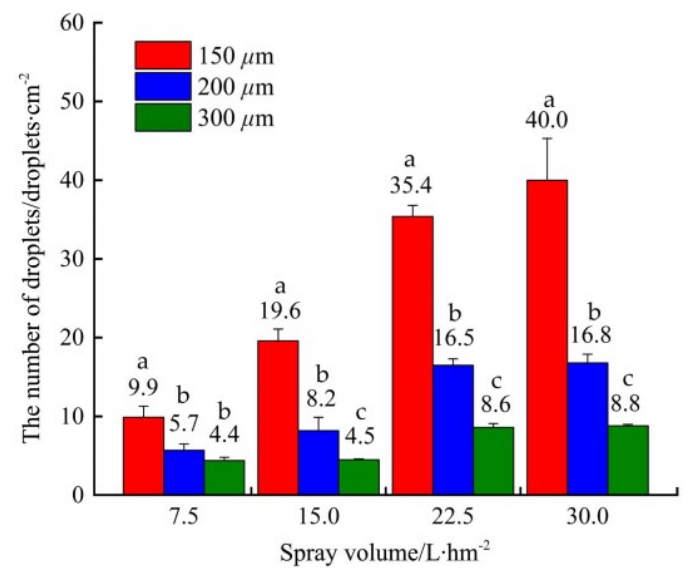

Note: Lowercase letters represent the significant difference in the number of droplets between different droplet sizes with the same spray volume

Figure 6 The number of droplets under different spray volumes

Previous studies have shown that the number of droplets increased with decreasing the droplet $\operatorname{size}^{[37-40]}$, which was consistent with our research results. However, small droplets also will lead to serious drift problems. Wang et al. ${ }^{[21]}$ studied the drift of different VMD of $100 \mu \mathrm{m}, 150 \mu \mathrm{m}$, and $200 \mu \mathrm{m}$, and the deposition at different downwind distances generally decreased with the increase of VMD. The number of droplets was also affected by the spray volume. Generally speaking, the number of droplets increased with the increase of the spray volume. The decrease of droplet size had little influence on the number of droplets in large volume spraying ${ }^{[1,42]}$. This may be related to that the droplets were more prone to overlap under the large volume application. The lower volume application used in our research may be the reason for the significant influence of droplet size.

The number of droplets was critical to the effect of control efficacy $^{[43]}$. Increasing the number of droplets can increase the probability of pesticide contact with the target and may improve the control efficiency, but the effect of contact or systemic pesticides were different ${ }^{[44]}$. Ferguson et al. ${ }^{[27]}$ found that the reduction in the number of droplets affected the efficacy of contact herbicide of paraquat and amitrole, but not systemic herbicides like clodinafop, glyphosate, and imazamox plus imazapyr. $\mathrm{Xu}$ et al. ${ }^{[45]}$ experimented on the control of the rice leaf roller with chlorobenzene found that the control effect decreased with the decrease of the number of droplets at lower volume application. This means that even high-concentration pesticides require a certain number of droplets to achieve good control efficacy. Syngenta Crop Protection AG (Basel, Switzerland) recommended at least 20-30 droplets $/ \mathrm{cm}^{2}$ for pre-emergence herbicide applications, 30-40 droplets $/ \mathrm{cm}^{2}$ reaching the critical threshold for contact post-emergence herbicide applications ${ }^{[46]}$. Therefore, it was necessary to consider not only the influence of spray volume and droplet size but also the pesticide type, weeding time.

\subsection{Droplets distribution}

Grasping the uniformity of droplet distribution is of great importance to control the spray process ${ }^{[24]}$. It can be seen from Figure 7 and Figure 8 that the coefficients of variation of the percentage of spray coverage and the number of droplets were $29.0 \%-73.3 \%$ and $20.2 \%-54.1 \%$, respectively. When the spray volume was $15.0 \mathrm{~L} / \mathrm{hm}^{2}$ and the droplet size was $150 \mu \mathrm{m}$, the percentage of spray coverage and the number of droplet distribution were the most uniform, and the coefficient of variation was $29.0 \%, 20.2 \%$, respectively. When the spray volume was $30.0 \mathrm{~L} / \mathrm{hm}^{2}$ and the droplet size was $300 \mu \mathrm{m}$, the distribution of the percentage of spray coverage was the worst with the coefficient of variation of $73.3 \%$. When the spray volume was $7.5 \mathrm{~L} / \mathrm{hm}^{2}$ and the droplet size was $300 \mu \mathrm{m}$, the distribution of the number of droplets was the worst with the coefficient of variation of $54.1 \%$. This scenario occurs may be related to flight parameters and rotor wind during our experiment. Meanwhile, the analysis found that the droplet size and spray volume did not have significant differences in the uniformity of the droplet distribution.

The uniformity of the deposition distribution of the UAV was influenced by many factors, such as the flight parameters ${ }^{[9]}$, the equipment parameters ${ }^{[12]}$, the spraying system $^{[19]}$, and the meteorological condition ${ }^{[12]}$. Qin et al. ${ }^{[9]}$ found that the best uniformity of droplet deposition was when the flight height and speed were $1.5 \mathrm{~m}$ and $5 \mathrm{~m} / \mathrm{s}$, respectively. Wahla et al. ${ }^{[12]}$ used helicopters to test spray uniformity at different heights and nozzle openings. The results showed that a good uniformity was achieved when the flight height was $1.5 \mathrm{~m}$ and the nozzle openings (discharge rate) were 50\%,75\% and 100\%. Meanwhile, they also studied the effect of wind speed on the uniformity of droplet deposition, and the results showed that the uniformity of droplet deposition decreased with the increase of the wind speed. Koo et al. ${ }^{[19]}$ developed a roll-balanced agricultural helicopter with an elevated-pylon tail rotor system to solve the problem of most agricultural helicopters exhibiting biased downwash, increasing the uniformity of the distribution of droplet deposition. The uniformity of droplet deposition was also related to the rotor wind of the UAV. Ahmad et al. ${ }^{[1]}$ found in their study that helicopter rotor wind made the fine and coarse droplets unable to be evenly distributed during deposition.

The uniformity of droplet deposition was essential for optimal pesticide application. Poor uniformity of the spray distribution may reduce the quality of the application, increase resistance, and increase usage of the dosage. In some cases, the lack of uniformity also may cause damage to the crop, especially when spraying fungicides and herbicides. Qin et al. ${ }^{[9]}$ found that the control effect increased with the increase of the droplet distribution uniformity. Studies at the pest stages and sedentary pests using contact insecticides have shown that the more uniformly distributed the insecticides on the leaf surface, the higher the control efficiency ${ }^{[47,48]}$. Meanwhile, the effect of uniformity on herbicide efficacy was also critical. Pierce et al. ${ }^{[49]}$ research showed that when the pulse width modulation duty cycle was $25 \%$, the coefficient of variation was as high as $65 \%$. This non-uniform spraying method reduces the performance of the herbicide by $35 \%$ during the entire spraying process. Therefore, it was necessary to improve control efficacy by improving the uniformity of the droplet deposition. 

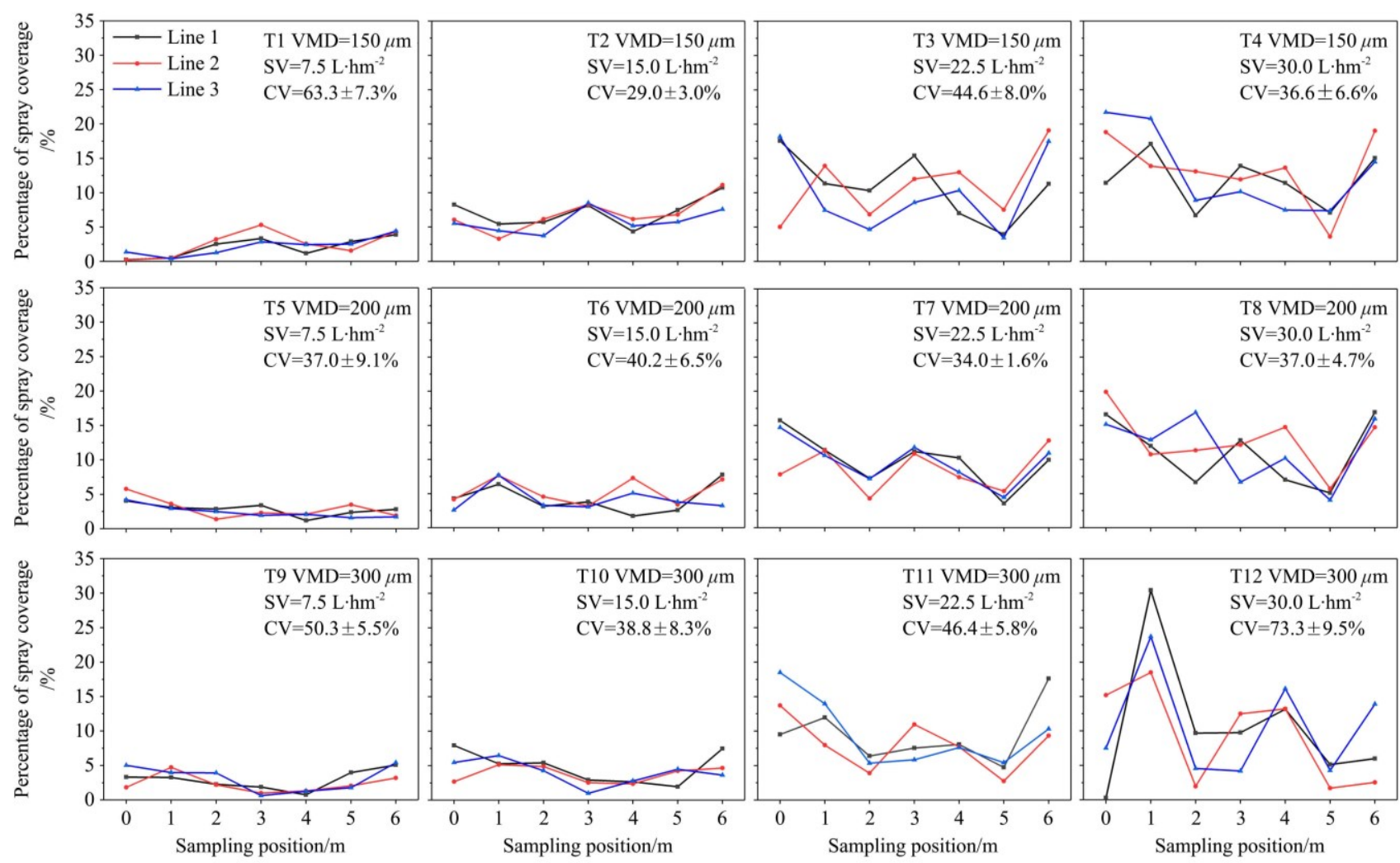

Note: VMD: volume median diameter; SV: Spray volume; CV: Coefficient of variation, Mean \pm standard error.

Figure 7 The percentage of spray coverage of different treatment at each sampling point
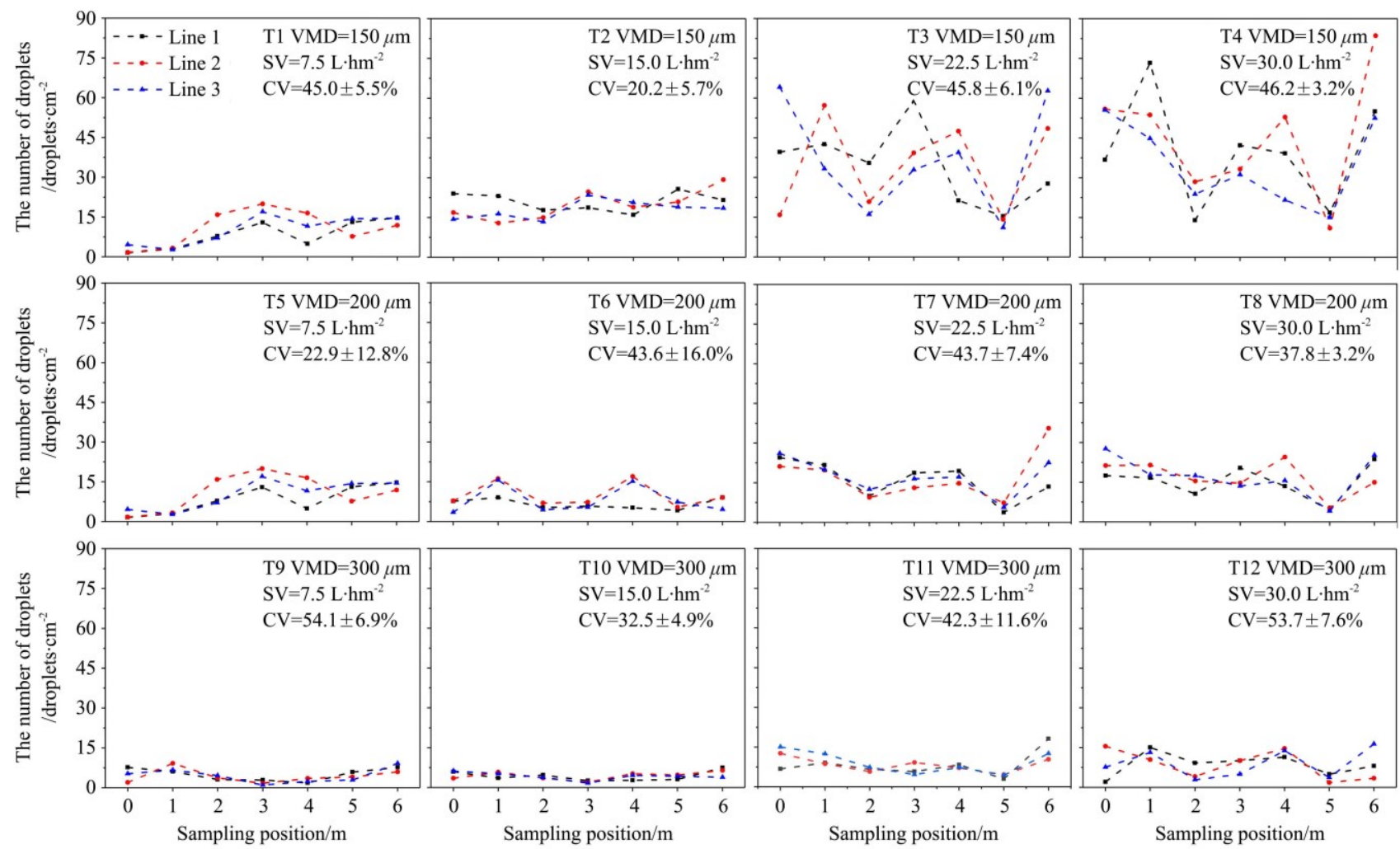

Note: VMD: volume median diameter; SV: Spray volume; CV: Coefficient of variation, Mean \pm standard error.

Figure 8 The number of droplets of different treatment at each sampling point

\section{Conclusions}

In this study, the effect of four different spray volumes and three different droplet sizes on droplet deposition were tested in winter wheat fields. The percentage of spray coverage and the number of droplets were used to reflect the deposition quality.
The conclusions are as follows:

1) When the spray volume was $7.5 \mathrm{~L} / \mathrm{hm}^{2}$, the effect of VMD on the percentage of spray coverage was not significant. When the spray volume was $\geq 15.0 \mathrm{~L} / \mathrm{hm}^{2}$, these variation rules were changed to smaller droplets with greater coverage.

2) The number of droplets decreases with the increase of 
droplet size and the decrease of the spray volume.

3) The droplet size and spray volume did not have a significant effect on the uniformity of the deposition. When the spray volume was $15.0 \mathrm{~L} / \mathrm{hm}^{2}$ and the droplet size was $150 \mu \mathrm{m}$, the percentage of spray coverage and the number of droplet distribution were the most uniform, and the coefficient of variation was $29.0 \%, 20.2 \%$, respectively.

The experiment demonstrated that the droplet size and spray volume are important factors affecting droplet deposition for pesticide spraying by crop protection UAV. However, the uniformity of the droplet deposition also needs to be improved by adding additives or optimizing the spraying system.

\section{Acknowledgements}

The authors acknowledge that this work was financially supported by the Leading Talents of Top Talents Program for One Case One Discussion of Shandong Province; the Development Special Funds on Science and Technology to Guide Local by the Central Government: "Research and Development on Technology and Equipment of Precision Agriculture Aviation"; Science and Technology Development Program of Zibo (Grant No. 2018kj010073), Program of Shandong Provincial Collaborative Innovation Center of Dry-farming Intelligent Agricultural Equipment; Young Innovative Talents Project of Regular Institutions of Higher Education of Guangdong Province (Grant No. 2018KQNCX020); Key Science and Technology Plan of Guangdong Province (Grant No. 2017B010116003). The authors acknowledge Corteva Agroscience Technology (Shanghai) Co., Ltd for providing corresponding materials, and also thank reviewers and editors for giving relevant revision advice to improve the paper.

\section{[References]}

[1] Ahmad F, Qui B J, Dong X Y, Ma J, Huang X, Ahmed S, et al. Effect of operational parameters of UAV sprayer on spray deposition pattern in target and off-target zones during outer field weed control application. Computers and Electronics in Agriculture, 2020; 172: 105350. doi: 10.1016/j.compag.2020.105350.

[2] Wang G B, Lan Y B, Yuan H Z, Qi H X, Chen P C, Ouyang F, et al. Comparison of spray deposition, control efficacy on wheat aphids and working efficiency in the wheat field of the unmanned aerial vehicle with boom sprayer and two conventional knapsack sprayers. Applied Sciences, 2019; 9(2): 218. doi: 10.3390/app9020218.

[3] Chen Y, Qi H X, Li G, Lan Y B. Weed control effect of unmanned aerial vehicle (UAV) application in wheat field. Int J Precis Agric Aviat, 2018; 1(1): 25-31.

[4] Yang S L, Yang X B, Mo J Y. The application of unmanned aircraft systems to plant protection in China. Precision Agriculture, 2018; 1(2): 278-292.

[5] Lan Y B, Chen S D. Current status and trends of plant protection UAV and its spraying technology in China. Int J Precis Agric Aviat, 2018; 1(1): 1-9.

[6] Chen S D, Lan Y B, Zhou Z Y, Ouyang F, Wang G B, Huang X, et al. Effect of droplet size parameters on droplet deposition and drift of aerial spraying by using plant protection UAV. Agronomy, 2020; 10: 195 . doi: 10.3390/agronomy10020195.

[7] Meng Y H, Han Y X, Liang Z, Su J, Lan Y B. Harvest-aid application strategy in different cotton planting densities using UAV: Effects of dosage and application frequency on defoliation efficacy, boll opening rate, fiber quality, and lint cotton yield. Int J Precis Agric Aviat, 2019; 2(1): 31-41.

[8] Hunter J E, Gannon III T W, Richardson R J, Yelverton F H, Leon R G. Integration of remote-weed mapping and an autonomous spraying unmanned aerial vehicle for site-specific weed management. Pest Management Science, 2020; 76(4): 1386-1392.

[9] Qin W C, Qiu B J, Xue X Y, Chen C, Xu Z F, Zhou Q Q. Droplet deposition and control effect of insecticides sprayed with an unmanned aerial vehicle against plant hoppers. Crop Protection, 2016; 85: 79-88.

[10] Martinez G J, Agüera P, Agüera J, Pérez-Ruiz M. Spray and economics assessment of a UAV-based ultra-low-volume application in olive and citrus orchards. Precision Agriculture, 2020; 21(1): 1-18.

[11] Wang G B, Lan Y B, Qi H X, Chen P C, Hewitt A, Han Y X. Field evaluation of an unmanned aerial vehicle (UAV) sprayer: Effect of spray volume on deposition and the control of pests and disease in wheat. Pest Management Science, 2019; 75(6):1546-1555.

[12] Wahla S H, Cheema M J M, Arshad M, Chaat A A, Siddique S A. Spray uniformity testing of unmanned aerial spraying system for precise agro-chemical applications. Pakistan Journal of Agricultural Sciences, 2019; 56: 897-903.

[13] Guo S, Li J Y, Yao W X, Zhan Y L, Li Y F, Shi Y Y. Distribution characteristics on droplet deposition of wind field vortex formed by multi-rotor UAV. Plos One, 2019; 14(7): e220024. doi: 10.1371/journal.pone.0220024.

[14] Zhu H, Jiang Y, Li H Z, Li J X, Zhang H H. Effects of application parameters on spray characteristics of multi-rotor UAV. Int J Precis Agric Aviat, 2019; 2(1): 18-25.

[15] Chen S D, Lan Y B, Li J Y, Zhou Z Y, Liu A, Mao Y D. Effect of wind field below rotor of unmanned helicopter on droplet deposition distribution of aerial spraying. Int J Agric \& Biol Eng, 2017; 10(3): 67-77.

[16] Zhang P, Wang K J, Qiang L Y, He S L, Yi S L, Xie R G, et al. Droplet distribution and control against citrus leaf miner with UAV spraying. International Journal of Robotics and Automation, 2017; 32(3): 299-307.

[17] Jee S, Jeon B, Cho H C. Implementation of aerial application system for application uniformity. The Korea Academia-Industrial Cooperation Society, 2016; 17(1): 597-604. (in Korean)

[18] Xue X Y, Lan Y B, Sun Z, Chang C, Hoffmann W C. Develop an unmanned aerial vehicle based automatic aerial spraying system. Computers and Electronics in Agriculture, 2016; 128: 58-66.

[19] Koo Y M, Bae Y H, Seok T S, Shin S K, Park H J. Tail rotor design and thrust test for a roll-balanced agricultural unmanned helicopter. Journal of Biosyistems Engineering, 2010; 35: 302-309.

[20] Hunter J E, Gannon T W, Rochardson R J, Yelverton F H, Leon R G Coverage and drift potential associated with nozzle and speed selection for herbicide applications using an unmanned aerial sprayer. Weed Technology, 2020; 34: 235-240.

[21] Wang G B, Han Y X, Li X, Andaloro J, Chen P C, Hoffmann, W C, et al. Field evaluation of spray drift and environmental impact using an agricultural unmanned aerial vehicle (UAV) sprayer. Science of the Total Environment, 2020; 737: 139793. doi: 10.1016/j.scitotenv.2020.139793.

[22] Bird S L, Esterly D M, Perry S G. Off-target deposition of pesticides from agricultural aerial spray applications. Journal of Environmental Quality, 1996; 25(5): 1095-1104.

[23] Chechi A, Roehrig R, Piton B. The combined use of spray volumes and droplet sizes in the chemical control of Asian soybean rust in cultivars with different leaf area indices. Crop Protection, 2020; 136: 105212. 10.1016/j.cropro.2020.105212.

[24] Knoche M. Effect of droplet size and carrier volume on performance of foliage-applied herbicides. Crop Protection, 1994; 13(3): 163-178.

[25] Butts T R, Samples C A, Franca L X, Dodds D M, Reynolds D B, Adams J W, et al. Spray droplet size and carrier volume effect on dicamba and glufosinate efficacy. Pest Management Science, 2018; 74(9): 2020-2029.

[26] Berger S T, Dobrow M H, Ferrell J A, Webster T M. Influence of carrier volume and nozzle selection on palmer amaranth control. Peanut Science, 2014; 41(2): 120-123.

[27] Ferguson J C, Chechetto R G, Adkins S W, Hewitt A J, Chauhan B S, Kruger $\mathrm{G} \mathrm{R}$, et al. Effect of spray droplet size on herbicide efficacy on four winter annual grasses. Crop Protection, 2018; 112: 118-124.

[28] Creech C F, Henry R S, Werle R, Sandell L D, Hewitt A J, Kruger G R. Performance of postemergence herbicides applied at different carrier volume rates. Weed Technology; 2015; 29(3): 611-624.

[29] Creech C F, Moraes J G, Henry R S, Luck J D, Kruger G R. The impact of spray droplet size on the efficacy of 2,4-D, atrazine, chlorimuron-methyl, dicamba, glufosinate, and saflflufenacil. Weed Technol, 2016; 30: 573-586.

[30] Cao L D, Cao C, Wang Y, Li X H, Zhou Z L, Li F M, et al. Visua determination of potential dermal and inhalation exposure using allura red as an environmentally friendly pesticide surrogate. ACS Sustainable Chemistry \& Engineering, 2017; 5(5): 3882-3889.

[31] Wang S L, Song J L, He X K, Song L, Wang X N, Wang C L, et al. Performances evaluation of four typical unmanned aerial vehicles used for pesticide application in China. Int J Agric Biol Eng, 2017; 10(4): 22-31.

[32] Ebert T A, Taylor R, Downer R A, Hall F R. Deposit structure and efficacy of pesticide application. 1: Interactions between deposit size, toxicant concentration and deposit number. Pesticide Science, 1999; 55(8): 
783-792.

[33] Xiao Q G, Xin F, Lou Z X, Zhou T T, Wang G B, Han X Q, et al. Effect of aviation spray adjuvants on defoliant droplet deposition and cotton defoliation efficacy sprayed by unmanned aerial vehicles. Agronomy, 2019; 9: 217. doi: 10.3390/agronomy9050217.

[34] Merrltt C R. The influence of form of deposit on the phytotoxicity of difenzoquat applied as individual drops to Avena fatua. Annals of Applied Biology, 2008; 101(3): 517-525.

[35] Ramsdale B K, Messersmtth C G. Nozzle, spray volume, and adjuvant effects on carfentrazone and imazamox efficacy. Weed Technology, 2001; 15(3): 485-491.

[36] Robert E E, William E H, Robert M H. Effect of venturi-type nozzles and application volume on postemergence herbicide efficacy. Weed Technology, 2001; 15: 75-80.

[37] Bryant J E, Yendol W G. Evaluation of the influence of droplet size and density of bacillus thuringiensis against gypsy moth larvae (Lepidoptera: Lymantriidae). Journal of Economic Entomology, 1988; 81(1): 130-134.

[38] Alm S R, Reichard D L, Hall F R. Effects of spray drop size and distribution of drops containing bifenthrin on tetranychus urticae (Acari: Tetranychidae). Journal of Economic Entomology, 1987; 80(2): 517-520.

[39] Adams A J, Hall F R. Initial behavioural responses of aphis gossypii to defined deposits of bifenthrin on chrysanthemum. Crop Protection, 1990; 9 : 39-43.

[40] Bouse L F, Whisenant S G, Carlton J B. Aerial spray deposition on mesquite. Transactions of the ASABE, 1992; 35(1): 51-59.

[41] Lee A W, Miller P C H, Power J D, Cross J V, Gilbert A J, Glass C R, et al. The application of pesticide sprays to tomato crops. Aspects of Applied
Biology, 2000; 57: 383-390.

[42] Rincon V J, Sanchezhermosilla J, Paez F, Perezalonso J, Callejon A J. Assessment of the influence of working pressure and application rate on pesticide spray application with a hand-held spray gun on greenhouse pepper crops. Crop Protection, 2017; 96: 7-13.

[43] Xiao Q G, Du R, Zhou T T, Han X Q, Wang G B, Fu W. Effects of alkyl ethyl sulfonate dosage on cotton defoliation efficacy sprayed by UAV. Int J Precis Agric Aviat, 2019; 2: 67-75.

[44] Beresford L C, Roger D S, Keith R K, Robert E K. Efficacy evaluation of a reduced dosage of tebufenozide applied aerially to control spruce budworm (Choristoneura fumiferana). Crop Protection, 2005; 24(6): 557-563.

[45] Xu D J, Gu Z Y, Xu G C, Xu X L, Dong Y X. Effects of droplet density and droplet size on control efficiency of chlorantraniliprole against cnaphalocrocis medinalis (Guenée). Scientia Agricultura Sinica, 2012; 45(4): 666-674.

[46] Zhu H, Salyani M, Fox R D. A portable scanning system for evaluation of spray deposit distribution. Computers and Electronics in Agriculture, 2011; 76(1): 38-43.

[47] Munthali D C. Biological efficiency of small dicofol droplets against tetranychus urticae (Koch) eggs, larvae and protonymphs. Crop Protection, 1984; 3(3): 327-334.

[48] Munthali D C, Wyatt I J. Factors affecting the biological efficiency of small pesticide droplets against Tetranychus urticae eggs. Pesticide Science, 1986; 17(2): 155-164.

[49] Pierce R A, Ayers P D. Evaluation of deposition and application accuracy of a pulse width modulation variable rate field sprayer. 2001 ASAE Annual International Meeting, Sacramento, USA, July 30-August 1, 2001. 